\title{
State anxiety and depression as factors modulating and influencing postoperative pain in dental implant surgery. A prospective clinical survey
}

\author{
Rafael Gómez-de Diego ${ }^{1}$, Antonio Cutando-Soriano ${ }^{2}$, Javier Montero-Martín ${ }^{3}$, Juan-Carlos Prados-Frutos ${ }^{4}$, \\ Antonio López-Valverde ${ }^{5}$
}

\footnotetext{
${ }^{1}$ Profesor Asociado. Departamento Ciencias de la Salud. Universidad Alfonso X El Sabio. Madrid

${ }^{2}$ Profesor Titular. Departamento de Estomatología. Universidad de Granada

${ }^{3}$ Profesor Contratado Doctor. Departamento de Cirugía. Universidad de Salamanca

${ }^{4}$ Profesor Titular. Departamento de Estomatología. Universidad Rey Juan Carlos. Madrid

${ }^{5}$ Profesor Contratado Doctor. Departamento de Cirugía. Universidad de Salamanca
}

Correspondence:

Universidad de Salamanca

anlopezvalverde@gmail.com

Received: 04/12/2013

Accepted: $18 / 02 / 2014$

Gómez-de Diego R, Cutando-Soriano A, Montero-Martín J, Prados-Frutos JC, López-Valverde A. State anxiety and depression as factors modulating and influencing postoperative pain in dental implant surgery. A prospective clinical survey. Med Oral Patol Oral Cir Bucal. 2014 Nov 1;19 (6):e592-7.

http://www.medicinaoral.com/medoralfree01/v19i6/medoralv19i6p592.pdf

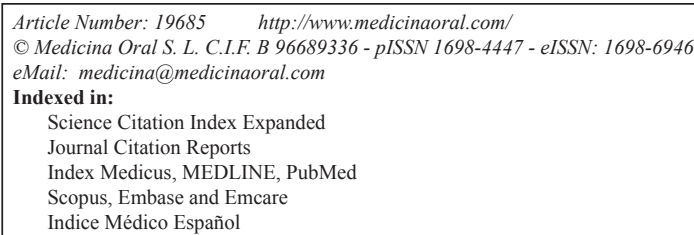

\begin{abstract}
Objetives: To determine whether preoperative state anxiety and depression modulate or influence objective and subjective postoperative pain following dental implant insertion.

Study Design: Prospective, clinical study with 7-day follow-up of a sample of 105 subjects who preoperatively completed the state anxiety questionnaire (STAI-E) and Beck Depression Inventory (BDI) and postoperatively, at 2 and 7 days, recorded objective pain with the Semmes-Weinstein mechanical esthesiometer (SW test) and subjective pain with the Visual Analog Scale (VAS).

Results: $85.6 \%$ and $81.5 \%$ of patients, respectively, recorded no signs of state anxiety or depression. The correlation between anxiety and depression for both maxillary bones was the lower $(P=0.02)$. The correlation between subjective and objective pain at 2 and 7 days, and the anatomic regions intervened, was statistically significant in the mandible at day $7(P<0.01)$, and highly significant $(P<0.001)$ for the other variables. The correlation between state anxiety and objective pain at day 7 was nearly statistically significant $(P=0.07)$.

Conclusions: The correlation between state anxiety and depression, and objective and subjective pain at day 7 was not statistically significant. A strong correlation was found between objective and subjective pain in the immediate postoperative period.
\end{abstract}

Key words: Anxiety, depression, postoperative pain, dental implants. 


\section{Introduction}

Historically, pain has been considered a mode of somatic sensation. Today, the International Association for the Study of Pain (IASP) defines it as: "An unpleasant sensory and emotional experience associated with actual or potential tissue damage, or described in terms of such damage", (1) leading us to understand pain as a perception implying four essential issues: sensitivity to certain tissue alterations interpreted as harmful to the integrity of the subject, the chance that pain might have a non-somatic cause justifying it and the existence of an subjective emotional component (2).

Superficial or deep somatic pain relates the damaged area to the perception of damage suffered. The surgical lesion caused by dental implant insertion triggers biochemical processes at the implant site and in the central and peripheral nervous system. This causes physiological reactions (transduction, transmission, modulation and perception) which, as we have seen, imply sensorial, motor, neurovegetative, emotional and memory responses. Consequently, the perception of pain is not just an impulse running through a nerve but an integrated process including the perception of a potentially noxious sensorial input, rapid evaluation of the noxious stimulus, the elaboration of a biological response, and the construction of an attitude towards the pain.

Dental implant treatments are a predictable therapeutic alternative widely used in dentistry to attain all three facets of oral rehabilitation: the morphological, aesthetic and functional (3-5).

Given that the characteristics of pain are modulated by physiological mechanisms like anxiety and depression, $(2,6)$ among other factors, the present study analyzes the association between these mechanisms and objective and subjective postoperative pain. In a longitudinal prospective study, we analyze objective and subjective pain in the postoperative period following dental implant insertion as dependent variables, and correlate these with state anxiety and depression. At the outset of our study, we consider that state anxiety and depression modulate or influence objective and subjective postoperative pain.

\section{Material and Methods}

The present study was conducted in accordance with the principles of the World Medical Association Declaration of Helsinki (8th revision, 2008 http://www.wma.net/e/ polic/b3.htm) on medical research involving human subjects. All participants were made aware of the methodology and all gave written informed consent.

The study was conducted in four dental clinics in the autonomous region of Madrid (Spain) between May and December 2009. The study population consisted of 105 patients who met the inclusion criteria: age over 18 years, with no significant systemic diseases (ASA I or II), of both sexes, and indicated for dental implants. The patients were selected in consecutive non-probabilistic sampling, with the unit of analysis being each individual.

To determine objective pain we used the SemmesWeinstein mechanical esthesiometer (SW test) (TouchTestTM; North Coast Medical, Morgan Hill, USA). The SW test provides a numeric rating of the tactile pain threshold using a mechanical stimulus measured in grams (7). Twenty nylon monofilaments, of equal length but different diameters, provide a logarithmic scale of applied real strength and a linear scale of perceived intensity. The values obtained (Table 1) range from 1.65

Table 1. Relationship between filament diameter and strength expressed in grams.

\begin{tabular}{|c|c|}
\hline Size (mm) & Strength (g) \\
\hline 1.65 & 0.008 \\
\hline 2.36 & 0.02 \\
\hline 2.44 & 0.04 \\
\hline 2.83 & 0.07 \\
\hline 3.22 & 0.16 \\
\hline 3.61 & 0.4 \\
\hline 3.84 & 0.6 \\
\hline 4.08 & 1 \\
\hline 4.17 & 1.4 \\
\hline 4.31 & 2 \\
\hline 4.56 & 4 \\
\hline 4.74 & 6 \\
\hline 4.93 & 8 \\
\hline 5.07 & 10 \\
\hline 5.18 & 15 \\
\hline 5.46 & 26 \\
\hline 5.88 & 60 \\
\hline 6.10 & 100 \\
\hline 6.45 & 180 \\
\hline 6.65 & 300 \\
\hline & \\
\hline & \\
\hline
\end{tabular}

$\mathrm{mm}$ to $6.65 \mathrm{~mm}$ diameter and are equivalent to 0.008 grams and 300 grams force pressure. The filaments, starting with the smallest diameter, are applied perpendicular to the masticatory mucosa in the intervention zone until they bend. In the absence of any response, and after a 30 -second pause, the test is repeated using a monofilament with a larger diameter, until the participant recognizes the stimulus.

The Visual Analog Scale (VAS) measures one-dimensional subjective pain intensity on a 10-level scale representing a continuous spectrum of the experience of pain from " 0 " =no pain to " 10 "=severe/unbearable pain (8). Patients' perceptions of pain level were recorded. 
Analysis of the variables anxiety and depression were recorded through two self-rating tests: the STAI-E questionnaire, with 20 items of 4 options each on a standard Likert scale coded from 0 to 3 , establishing patient state anxiety at 19 points in men and 21 points in women (9); and the psychometric BDI inventory, with 21 multiple choice questions. Patient selected responses that best suited their current situation to determine the intensity/ severity of depression. The total BDI score was the sum of response values, which vary on a 4-point scale. The range was from 0 to 63 points, with accepted cut-offs at 0 to 9 indicating no depression; 10 to 18 , mild to moderate depression; 19 to 29 , moderate-severe depression; and 30 points or more, severe depression (10).

The study was conducted using the standard protocol for dental implant insertion. Demographic and clinical data were collected from medical records. The independent variables-anxiety and depression-were measured the day before surgery and the dependent variablesobjective and subjective pain-at 2 and 7 days following surgery.

In a descriptive analysis, we used the mean, 95\% confidence interval (CI 95\%) and standard deviation (SD) to check for possible errors. To analyze relation strength, we performed bivariate correlation analysis between the quantitative variables using Pearson's correlation coefficient and the level of statistical significance. Analysis of the nature of the relation was with multiple stepwise linear regression to quantify the effect of the independent variables that best predict the objective and subjective pain scores at day 7 . In all cases, we established $P<0.05$ as statistically significant. Analysis was with SPSS 18.0 for Windows.

\section{Results}

Of 105 patients enrolled, 8 were excluded for not presenting the necessary documentation. Data analysis (Table 2) describes the 97 patients who participated in the study; $52.6 \%$ were women and $47.4 \%$ men, with an age range of 20 to 83 years $(49.4 \pm 15.4)$. Single implants $(68.0 \%)$ and multiple implants $(32.0 \%)$ were used; most $(51.5 \%)$ were inserted in the mandible. Whether in the mandible or upper maxillary bone, most implants $(80.5 \%)$ were in posterior anatomic regions.

The STAI-E questionnaire found 83 patients $(85.6 \%)$ had no state anxiety and 15 (14.4\%) had scores in excess of 20 , reflecting a mean questionnaire total of $13.3 \pm 6.8$. The BDI inventory found 79 patients had no depression; 18 , mild depression; and 0, moderate or severe depression; the mean total inventory score was $5.0 \pm 5.4$.

Postoperative pain was determined at 2 and 7 days (Fig. 1). At day 7 , the VAS found $88.6 \%$ of patients had improved, versus $11.3 \%$ who indicated feeling worse or the same; the SW test found $90.7 \%$ of patients showed improvement versus $9.3 \%$ who indicated feeling worse or the same.
Table 2. Clinical and sociodemographic description of sample $(\mathrm{n}=97)$.

\begin{tabular}{|c|c|c|c|}
\hline & & Mean & $\boldsymbol{\sigma}$ \\
\hline \multicolumn{2}{|l|}{ Age: Years } & 49.4 & 15.4 \\
\hline & & $\mathbf{n}_{\mathrm{i}}$ & $\%$ \\
\hline \multirow[t]{2}{*}{ Sex } & Women & 51.0 & 52.6 \\
\hline & Men & 46.0 & 47.4 \\
\hline \multirow[t]{4}{*}{ Clinical data } & $\mathrm{N}^{\mathrm{o}} 1$ & 49.0 & 50.5 \\
\hline & $\mathrm{N}^{\mathrm{o}} 2$ & 40.0 & 41.2 \\
\hline & $\mathrm{N}^{\mathrm{o}} 3$ & 6.0 & 6.2 \\
\hline & $\mathrm{N}^{\circ} 4$ & 2.0 & 2.1 \\
\hline \multirow[t]{2}{*}{ Implant } & Single & 66.0 & 68.0 \\
\hline & Multiple & 31.0 & 32.0 \\
\hline \multirow{2}{*}{$\begin{array}{l}\text { Anatomic } \\
\text { area }\end{array}$} & M & 50.0 & 51.5 \\
\hline & MS & 47.0 & 48.5 \\
\hline \multirow{4}{*}{$\begin{array}{l}\text { Anatomic } \\
\text { region }\end{array}$} & MRP & 44.0 & 45.4 \\
\hline & MSRP & 34.0 & 35.1 \\
\hline & GA & 13.0 & 13.4 \\
\hline & VS & 6.0 & 6.2 \\
\hline
\end{tabular}

$\sigma:$ Standard deviation

$\%$ : Percentage

ni: Absolute frequency

M: Mandible

UM: Upper maxillary bone

PMR: Posterior mandible region

PUMR: Posterior upper maxillary region

AG: Anterior group

SS: Several sectors

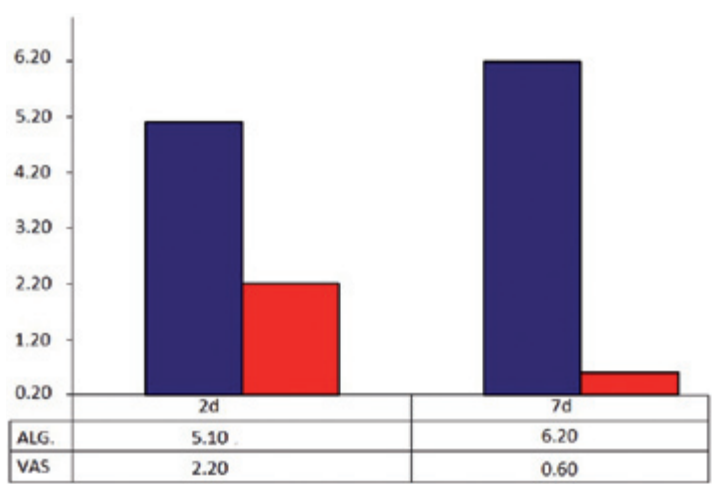

Fig. 1. Record of objetive and subjetive painal day 2 and day 7 .

Using Pearson's correlation coefficient and the level of statistical significance for the sample, bivariate correlation analysis (Table 3 ) of the relations between anxiety/depression, objective and subjective pain and the anatomic region, found a significant relation between anxiety and depression and the mandible $(P=0.02)$ and a nonsignificant relation with the upper maxillary bone $(P=0.34)$. The correlation between objective and subjective pain at 2 and 7 days with the same independent var- 
Table 3. Analysis of bivariate correlations $(\mathrm{n}=97)$.

\begin{tabular}{|l|c|c|c|c|}
\hline & \multicolumn{2}{|c|}{$\begin{array}{c}\text { Upper maxillary } \\
\text { bone }\end{array}$} & \multicolumn{2}{c|}{ Mandible } \\
\cline { 2 - 5 } & $\boldsymbol{\rho}$ & $\boldsymbol{\alpha}$ & $\boldsymbol{\rho}$ & $\boldsymbol{\alpha}$ \\
\hline $\begin{array}{l}\text { Beck depression } \\
\text { inventory Total - } \\
\text { STAI Total }\end{array}$ & 0.14 & 0.34 & 0.32 & 0.02 \\
\hline EVA 2d - EVA 7d & 0.55 & 0,001 & 0.43 & 0.01 \\
\hline $\begin{array}{l}\text { EMS-W 2d - } \\
\text { EMS-W 7d }\end{array}$ & 0.52 & 0,001 & 0.53 & 0,001 \\
\hline
\end{tabular}

$\rho$ : Pearson's correlation coefficient

$\alpha$ : Statistical significance: $\mathrm{p}$

VAS at 2 and 7 days: Subjective pain at 2 and 7 days

SW test: Objective-Subjective Pain at 2 and 7 days

iable was bilateral and significant, with a greater degree of significance $(P<0.001)$ in the relation between objective pain in both upper and lower maxillary bones.

The correlation between anxiety and depression and objective and subjective pain at 2 and 7 days indicated the potential value of conducting multiple stepwise linear regression analysis to quantify the variables' effect on objective and subjective pain. The general linear regression model for subjective pain at day 7 (Table 4) found a weak predictability coefficient (R2Adj $=0.24 ; \mathrm{F}=9.73$; $\mathrm{gl}=3, P<0.001$ ), with subjective pain at day 2 being the most significant variable $P<0.001$ and that which most influenced the dependent variable $(\beta=0.42)$. This led us to study the correlation between this, postoperative objective and subjective pain, and anatomic region (Table 5). The model found a strong predictability coefficient for both anatomic regions, with objective pain at day 7 , in the mandible, being the most significant $(P<0.001)$ and most influential $(\beta=-0.84)$ variable.

The general linear regression model for objective pain at day 7 (Table 6), recorded a moderate predictability coefficient, with postoperative objective pain at day 2 showing greater statistical significance $(P<0.001)$ and state anxiety giving a value close to significant. The moderate predictive capability of the model led us to explore the correlation between the same variable and subjective pain at 2 and 7 days in relation with anatomic regions (Table 7), with subjective pain at day 7 being the variable that recorded the greatest significance in both maxillary bones $(P<0.001)$, with greater statistical weight for the mandible $(\beta=-0.76)$.

\section{Discussion}

Our objective was to analyze in a prospective clinical study, objective and subjective pain in the short-term postoperative period and the correlation with state anxiety and depression. The sampling points were convenient and consecutive, so the representativity of the
Table 4. General stepwise linear regression model of subjective pain assessment at day $7(\mathrm{n}=97)$.

\begin{tabular}{|c|c|c|c|}
\hline $\mathbf{V}$ & $\mathbf{B}$ & $\boldsymbol{\beta}$ & $\boldsymbol{\alpha}$ \\
\hline $\mathrm{SI}-\mathrm{MI}$ & -0.47 & -0.19 & 0.04 \\
\hline UM - M & -0.45 & -0.19 & 0.03 \\
\hline VAS 2d & 0.30 & 0.42 & 0,001 \\
\hline \multicolumn{3}{|c|}{$\mathbf{R}^{\mathbf{2}} \mathbf{A d j}=\mathbf{0 . 2 4} ; \mathbf{F}=\mathbf{9 . 7 3} ; \mathbf{g l}=\mathbf{3}, \boldsymbol{p}<\mathbf{0 . 0 0 1}$} \\
\hline
\end{tabular}

V. variables analyzed

B: Non-standardized coefficients

$\beta$ : Standardized coefficients

$\alpha$ : Statistical significance: $\mathrm{p}$

SI: Single implant

MI: Multiple implant

UM: Upper maxillary bone

M: Mandible

VAS 2d: Subjective Pain at day 2

Table 5. General stepwise linear regression model of subjective pain assessment at day 7 in mandible and upper maxillary bone $(\mathrm{n}=97)$

\begin{tabular}{|c|c|c|c|}
\hline $\mathbf{V}$ & $\mathbf{B}$ & $\boldsymbol{\beta}$ & $\boldsymbol{\alpha}$ \\
\hline Mandible \\
\hline VAS 2d: & 0.31 & 0.32 & 0.01 \\
\hline SW test 2 & 0.56 & 0.35 & 0.01 \\
\hline SW test 7 & -1.68 & -0.84 & 0,001 \\
\hline \multicolumn{4}{|c|}{$\mathrm{R}^{2} \mathrm{Adj}=0.83 ; \mathrm{F}=34.31 ; \mathrm{gl}=6, \mathrm{p}<0.001$} \\
\hline Upper maxillary bone \\
\hline SW test 7 & -0.56 & -0.38 & 0.01 \\
\hline \multicolumn{4}{|c|}{$\mathbf{R}^{\mathbf{2}} \mathbf{A d j}=\mathbf{0 . 6 8} ; \mathbf{F}=\mathbf{4 6 . 9 1 ;} \mathbf{g l}=\mathbf{2}, \boldsymbol{p}<\mathbf{0 . 0 0 1}$} \\
\hline
\end{tabular}

V. variables analyzed

B: Non-standardized coefficients

$\beta$ : Standardized coefficients

$\alpha$ : Statistical significance: $\mathrm{p}$

VAS 2d: Subjective Pain at day 2

SW test 2 and 7 days: Objective Pain at 2 and 7 days

Table 6. General stepwise linear regression model of objective pain assessment at day $7(\mathrm{n}=97)$.

\begin{tabular}{|l|c|c|c|}
\hline \multicolumn{1}{|c|}{$\mathbf{V}$} & $\mathbf{B}$ & $\boldsymbol{\beta}$ & $\boldsymbol{\alpha}$ \\
\hline VAS 7d & -0.42 & -0.78 & 0,001 \\
\hline SI - MI & -0.20 & -0.15 & 0.02 \\
\hline STAI total & -0.01 & -0.11 & 0.07 \\
\hline $\begin{array}{c}\mathbf{R}^{2} \mathbf{A d j}=\mathbf{0 . 6 9} \\
\mathbf{F = 5 2 . 0 5 ;} \mathbf{g l}=\mathbf{4}, \\
\boldsymbol{p}<\mathbf{0 . 0 0 1}\end{array}$ & & & \\
\hline
\end{tabular}

V. variables analyzed

B: Non-standardized coefficients

$\beta$ : Standardized coefficients

$\alpha$ : Statistical significance: $p$

VAS 2d: Subjective Pain at day 2

SI: Single implant

MI: Multiple implants 
Table 7. General stepwise linear regression model of objective pain assessment at day 7 in mandible and upper maxillary bone $(\mathrm{n}=97)$.

\begin{tabular}{|c|c|c|c|}
\hline $\mathbf{V}$ & $\mathbf{B}$ & $\boldsymbol{\beta}$ & $\boldsymbol{\alpha}$ \\
\hline Mandible \\
\hline VAS 2d: & -0.09 & -0.18 & 0.04 \\
\hline VAS 7d & -0.38 & -0.76 & 0,001 \\
\hline \multicolumn{4}{|c|}{$\mathbf{R}^{\mathbf{2}} \mathbf{A d j}=\mathbf{0 . 7 2} ; \mathbf{F}=\mathbf{6 1 . 1 6} ; \mathbf{g l}=\mathbf{2 ,} \boldsymbol{p}<\mathbf{0 . 0 0 1}$} \\
\hline Upper maxillary bone \\
\hline VAS 2d: & -0.07 & -0.24 & 0.06 \\
\hline VAS 7d & -0.42 & -0.59 & 0,001 \\
\hline \multicolumn{4}{|c|}{$\mathbf{R}^{\mathbf{2}} \mathbf{A d j}=\mathbf{0 . 5 5} ; \mathbf{F}=\mathbf{2 7 . 0 3 ;} \mathbf{g l}=\mathbf{2}, \boldsymbol{p}<\mathbf{0 . 0 0 1}$} \\
\hline
\end{tabular}

V. variables analyzed

B: Non-standardized coefficients

$\beta$ : Standardized coefficients

$\alpha$ : Statistical significance: $p$

VAS at 2 and 7 days: Subjective Pain at 2 and 7 days

sample could be similar to that found in a probabilistic sample. Short-term follow-up enabled us to determine intrasubject variations and minimize information bias. The results were analyzed using descriptive analysis, bivariate correlation, and multiple stepwise linear regression to check for confounding variables.

We have applied accepted, validated instruments that have produced sound results in many epidemiological studies $(2,7,10,11-15)$. The questionnaire used determines only the transitory "state" of anxiety when faced with a stressful situation, and not trait anxiety, as this is a stable characteristic in the individual and favours conscious nonperception of changes in apprehension and tension associated with stressful situations like dental implant surgery $(2,6,9)$.

The age range of patients (20-83 years) and postoperative follow-up coincided with other studies of the impact of oral surgery-derived pain. González-Santana et al. (11) report on subjective pain at 2,4,6,12 and 24 hours in a sample of Spanish patients (range: 25-69 years); in a Canadian population (range: $35-63$ years), Morin et al. (12) analyze postoperative pain three times a day during the first 24 hours; and in a sample of Danish patients (range: 23-77 years), Urban \& Wenzel (13) conducted a 3-day follow-up of subjective pain.

Bivariate correlation analysis (Table 3) using Pearson's correlation coefficient found a significant correlation $(P=0.02)$ between anxiety/depression and the mandible, similar to results reported by Vickers et al. (6) who, in their study of a sample of 438 patients, reported a statistically significant relation $(P<0.01)$ between the psychological mechanisms and greater postoperative pain intensity. These same authors found a significant correlation between objective-subjective pain at 2 and 7 days and anatomic region, corroborating the validity of the materials and methods used as they coincide with the recommendations of several authors. In a sample of 65 patients receiving dental implants in the lower maxillary bone, Abarca et al. (14) found a statistically significant relation $(P<0.03)$ when objectively determining postoperative pain using the SW test. Poort et al. (15) recommended using the VAS together with the SW test in their review of methods to determine sensitivity in the third branch of the trigeminal nerve in oral surgery and dental implants.

Furthermore, linear regression found no statistical significance $(P=0.03)$ in the relation between anatomic region and subjective pain at day 7 (Table 4), coinciding with Muller \& Ríos Calvo (16), who studied a similar sample $(n=75)$ with 2-year follow-up. These authors concluded the relation between postoperative pain and the anatomic region implanted was not statistically significant $(P>0.01)$. Recent studies describe how painful afference of the 2nd and 3rd branch of the trigeminal nerve activates the pain protection systems such that regions of the brain affected cannot identify whether the input comes from the upper maxillary bone or mandible $(17,18)$.

The general regression models for objective and subjective pain found statistically significant relations between subjective pain at day 2 and objective pain at day $7(P<0.001)$ (Table 4$)$ and between objective and subjective pain at day $7(P<0.01)$ (Table 6$)$. This indicates the relation between pain types, showing that patients with higher subjective pain scores at postoperative day 2 , also present higher scores at day 7, above all in the upper maxillary bone. These results coincide with several studies 11,14: in a sample of 92 patients, Urban \& Wenzel (13) found a statistically significant relation between subjective postoperative pain at day 1 and day 3, concluding that patients indicating higher levels of pain in the first test also do so in the second one. In a large sample ( $\mathrm{n}=234)$ studied to determine subjective pain intensity at days 2 and 7, Al-Khabbaz et al. (19) found the level of pain at day 7 associated with that recorded on day $2(\mathrm{OR}=38.69)$.

Linear regressio models for subjective (Table 5) and objective pain (Table 7) at day 7 and correlated with anatomic regions, found a statistically significant relation between subjective pain and postoperative subjective pain at day 2, and objective pain at days 2 and 7 in the mandible, and with objective pain only in the upper maxillary bone (Table 5). The objective pain model (Table 7) found a significant relation between subjective pain at day 7 in both regions $(P<0.001)$. Similar results to those reported by other authors $(14,15)$ who propose using objective and subjective tests together to calculate the prevalence of pain. In a 12-month prospective study, Walton (20) used subjective methods and the S-W mechanical esthesiometer to analyze neurosensorial abnormalities in patients undergoing mandible implants, find- 
ing that $24 \%$ had abnormal nervous sensations-shortterm dysesthesia or paresthesia. Feldman et al. (21) assessed subjective pain intensity in a randomized study $(\mathrm{n}=120)$ by comparing subperiosteal and endosseous orthodontic implant insertion with upper premolar extraction, associating pain with three surgical techniques and concluding that the group undergoing concomitant exodontia recorded greater pain at day $7(P<0.01)$.

The general model of objective pain (Table 6) found a nearly significant relation with state anxiety $(P=0.07)$. These results are comparable with a recent study at the University of Amsterdam (Holland) (22). In 160 patients undergoing oral surgery for third molar removal, the authors concludes that anxiety does not predict surgeryrelated pain. This contrast with results reported by Eli et al. (2) who, on determining the correlation between pre- and postoperative anxiety and acute postoperative pain in an implant insertion procedure for a sample of 60 patients, found the sensation of pain associated significantly with the level of patient anxiety. Such discrepancies between authors indicate the need for more analytical case studies and randomized, controlled, double blind studies, in which patients complete both STAI state and STAI trait questionnaires.

\section{Conclusions}

Patients more frequently reported less postoperative pain at day 7. Bivariate correlation analysis found a statistically significant relation $(P=0.02)$ between anxiety and depression in the mandible. Multiple stepwise linear regression suggests that preoperative state anxiety and depression do not modulate objective and subjective postoperative pain at day 7 . In the postoperative period immediately following dental implant insertion, a strong correlation exists between subjective and objective pain.

\section{References}

1. IASP.IASP taxonomy, changes in the 2011 list [serial on line] 2011 Jul. Disponible en: URL:http://www.iasppain.org/AM/Template. $\mathrm{cfm}$ ?Section=Pain_Definitions\&Template $=/ \mathrm{CM} / \mathrm{HTMLDisplay}$. cfm\&ContentID $=1728$.

2. Eli I, Schwartz-Arad D, Baht R, Ben-Tuvin H. Effect of anxiety on the experience of pain in implant insertion. Clin Oral Implants Res. 2003; $14: 115-8$

3. Zarb GA, Smith A. The longitudinal clinical effectiveness of osteointegrated dental implants: the Toronto study. Part I: Surgical results. J Prosthet Dent. 1990;63:451-7.

4. Zarb GA, Smith A. The longitudinal clinical effectiveness of osteointegrated dental implants: the Toronto study. Part II: The prosthetic results. J Prosthet Dent. 1990;64:53-61.

5. Albrektsson T, Wennerberg A. The impact of oral implants - past and future, 1966 - 2042. J Can Dent Assoc. 2005;71:327.

6. Vickers ER, Boocock H, Harris RD, Bradshaw J, Cooper M, Vickers P, Cannon P. Analysis of the acute postopertative pain experience following oral surgery: identification of "unaffected", "disabled" and "depressed, anxious and disabled" patient clusters. Aust Dent J. 2006;51:69-71.

7. Komiyama O, Gracely RH, Kawara M, Laat AD. Intraoral measurement of tactile and filament-prick pain threshold using shortened Semmes-Weinstein monofilaments. Clin J Pain. 2008;24:16-21.
8. de Santana Santos T, de Souza-Santos JAS, Martins-Filho PRS, da silva LCF, de Oliveira e silva ED, Gomes ACA. Prediction of postoperative facial swelling, pain and trismus following third molar surgery based on preoperative variables. Med Oral Patol Oral Cir Bucal.2013;18:e65-70.

9. Muglali M, Komerik N. Factors related to patient's anxiety before and after oral surgery. J Oral Maxillofac Surg. 2008;66:870-7.

10. Aben I, Verhey F, Lousberg R, Lodder J, Honig A. Validity of the Beck Depression Inventory, Hospital Anxiety and Depression Scale, SCL-90, and Hamilton Depression Rating Scale as screening instruments for depression in stroke patients. Psychosomatics. 2002;43:386-93.

11. González-Santana H, Pe-arrocha-Diago M, Guarinós-Carbó J, Balaguer-Martínez J. Pain and inflammation in 41 patients following the placement of 131 dental implants. Med Oral Patol Oral Cir Bucal.2005; 10:258-63.

12. Morin C, Lund JP, Villarroel T, Clokie CML, Feine JS. Differences Between the sexes in post-surgical pain. Pain. 2000;85:79-85.

13. Urban T, Wenzel A. Discomfort experienced after immediate implant placement associated with three different regenerative techniques. Clin Oral Implants Res. 2010;21:1271-7.

14. Abarca M, van Steenberghe D, Malevez C, De Ridder J, Jacobs R. Neurosensory disturbances alter immediate loading of implants in the anterior mandible: an inicial questionnaire approach followed by a psychophysical assesment. Clin Oral Investig. 2006;10:269-77.

15. Poort LJ, van Neck JW, van der Wal KG. Sensory testing of inferior alveolar nerve injuries: a review of methods used in prospective studies. J Oral Maxillofac Surg. 2009;67:292-300.

16. Muller E, Ríos Calvo MP. Pain and dental implantology: sensory quantification and affective aspects. Part I: At the private dental office. Implant Dent. 2001;10:14-22.

17. Nash PG, Macefield VG, Klineberg IJ, Gustin SM, Murray GM, Henderson LA. Bilateral activation of the trigeminothalamic tract by acute orofacial cutaneous and muscle pain in humans. Pain. 2010;151:384-93.

18. Weigelt A, Terekhin P, Kemppainen P, Dörfler A, Foster C. The representation of experimental tooth pain from upper and lower jaws in the human trigeminal pathway. Pain. 2010;149:529-38.

19. Al-Khabbaz AK, Griffin TJ, Al-Shammari KF. Assessment of pain associated with the surgical placement of dental implants. J Periodontol. 2007;78:239-46.

20. Walton JN. Altered sensation associated with implants in the anterior mandible: a prospective study. J Prosthet Dent. 2000;83:443-9. 21. Feldmann I, List T, Feldmann H, Bondemark L. Pain intensity and discomfort following surgical placement of orthodontic anchoring units and premolar extraction: a randomized controlled trial. Angle Orthod. 2007;7:578-85.

22. Van Wijk AJ, de Jongh A, Lindeboom JA. Anxiety sensitivity as a predictor of anxiety and pain related to third molar removal. J Oral Maxillofac Surg. 2010;68:2723-9.

\section{Conflicts of interests}

These data are the property of the authors and no commercial company has intervened in any way in the conduct of the trial or in the publication of the results. 